\title{
Increased risk of affective disorders in type 2 diabetes is minimized by sulfonylurea and metformin combination: a population-based cohort study
}

Mark L Wahlqvist ${ }^{1,2,3,4^{*}}$, Meei-Shyuan Lee ${ }^{2,3}$, Shao-Yuan Chuang ${ }^{1}$, Chih-Cheng Hsu ${ }^{1,5}$, Hsin-Ni Tsai ${ }^{1}$, Shu-Han Yu $u^{6,7}$ and Hsing-Yi Chang ${ }^{1}$

See related commentary http://www.biomedcentral.com/1741-7015/10/151

\begin{abstract}
Background: To confirm whether type 2 diabetes (T2DM) is an affective disorder (AD) precursor, and to establish possible effects of oral anti-hyperglycemic agents (OAAs).

Methods: A representative cohort of 800,000 subjects was obtained from the Taiwanese National Health Insurance database on 1 January 2000. Those with consistent data $(n=762,753)$ were followed up between 1 January 1996 and 31 December 2007. Over this period, we assessed the presence $(n=62,988)$ or absence $(n=699,795)$ of T2DM, and whether any OAA was used $(n=40,232)$ or not $(n=22,756)$. To compare the risk of AD by diabetic status, those with T2DM were matched for birth date and gender with those without T2DM. To assess the effect of OAAs, we considered those 50 years and over. Matched AD-free patients with T2DM on OAAs were compared with those without OAAs, for age, gender, locality, health service, Charlson Comorbidity Index. and diabetes diagnosis date to avoid immortal time bias. AD incidence densities, hazard ratios (HR) and 95\% confidence intervals (Cls) were calculated.

Results: Compared with diabetes-free subjects, the HR (95\% CI) for AD was 2.62 (2.31 to 2.98) for patients with T2DM who were not on OAAs, and 1.08 (0.99 to 1.18) for those who were on OAAs. The AD incidence density decreased from 91.1 to 39.4 per 10,000 person-years for patients on the combination of metformin and sulfonylurea. The HR ( $95 \% \mathrm{Cl}$ ) for AD was 0.92 (0.59 to 1.45) for those on metformin alone, 1.08 (0.84 to 1.38) for those on sulfonylurea alone, and $0.40(0.32$ to 0.50$)$ for the combined treatment, and the decrease was not related to sequence or insulin usage. Similar patterns were seen for incident AD exclusion for up to 3 years, although more so for bipolar than unipolar.
\end{abstract}

Conclusions: The incident AD risk is increased by 2.6 -fold in T2DM, and the combination of sulfonylurea and metformin minimizes this risk.

Keywords: Neurodegenerative disease, Taiwan, Mood, Depression, Metformin

\footnotetext{
* Correspondence: profmlw@nhri.org.tw

'Division of Preventive Medicine and Health Services Research, Institute of Population Health Sciences, National Health Research Institutes, 35 Keyan

Road, Zhunan Town, Miaoli, Taiwan 35053, ROC

Full list of author information is available at the end of the article
} 


\section{Background}

It has been recognized that mood and behavioral disorders may contribute to a co-existent clinical cluster with diabetes $[1,2]$. Depression and diabetes occur together to a greater extent than would be expected based on their respective separate prevalences [3-9]. There has been uncertainty about the nature of what has been regarded as a bidirectional pathogenesis of the two conditions [10], although a Canadian study failed to find evidence for diabetes being an antecedent for depression [11]. However, studies of European and North American populations do indicate that diabetes is a precursor of depression [12-14]. A meta-analysis estimated that depression is a greater precursor of diabetes than the reverse [15] and, in a Spanish cohort, the incident diabetes rate attributable to depression was 7\% [16]. To date, most of these studies have involved Caucasian populations, and there is little information about the issue in those ethnicities that are experiencing rapid and major increases in diabetes prevalence, such as northeast Asians. Over the period 1993 to 2008, the prevalence of diabetes in Taiwan had doubled for men, with an increase in the age-standardized rate from $4.6 \%$ to $9.3 \%$, although for women, it decreased from $7.9 \%$ to $6.4 \%$ [17]. The prevalence of major depression in Taiwan was relatively low at $1.5 \%$, compared with other populations; for instance it was $19.0 \%$ in Beirut [18]. However, by 2001, prevalence of major depression in older populations in Taiwan was 5.9\% [19], comparable with international figures. Huang's meta-analysis showed that depression was 1.53 times more prevalent among older people with chronic disease [20]. Given the increasing diabetes prevalence, corresponding changes in depression or affective disorder (AD) rates might be expected if there is causality.

The question of anti-hyperglycemic management in the prevention of depression or AD is likely to become an increasingly relevant public-health and clinical matter. There is increasing evidence that the therapeutic scope of the biguanide drug metformin extends beyond its current indications for hyperglycemia to the prevention ofpreviously poorly appreciated outcomes of diabetes. These include certain cancers $[21,22]$ and neurodegenerative disease, notably dementia [23], and Parkinson's disease [24]. There may be a shared pathogenesis between diabetes and dementia related to oxidative stress and mitochondrial dysfunction, together with bioenergetics and abnormal protein folding. Metformin may decrease any or all of these associations. In addition, metformin has been shown to reduce tau hyperphosphorylation, which plays a role in the formation of the neurofibrillary tangles in neurodegeneration [25]. It is conceivable that this might be relevant in neuropsychiatric disorders as well, because tauopathy is seen when depression is co-morbid with Alzheimer's disease [26]. In further support of this concept, the mood-stabilizer lithium also reduces neurofibrillary tangle development [27]. The extent to which these mechanisms are relevant to the development of depression or AD is unknown. Clarification on insulin resistance as a risk setting for depression or $\mathrm{AD}$, and the extent to which this might be avoided, is now of considerable importance as the incidence of glycemic disorders increases globally. Moreover, diabetes and pre-diabetes may each be underlying contributors to depression or $\mathrm{AD}$, because the glycemic disorder progresses with the potentially reinforcing and adverse metabolic effects of depression itself.

The lower directional effect of diabetes on depression compared with the reverse may be due to past nonrecognition of risk reduction for depression associated with diabetes therapy $[10,12-15]$. What may be of related consequence is the potential synergy of depression and diabetes for conventionally characterized diabetes complications such as retinopathy [28]. Thus, it is possible that some studies have not only under-recognized the effect of type 2 diabetes (T2DM) on depression because they have not distinguished between patients treated or not with oral anti-hyperglycemic agents (OAAs), but have also not recognized the mood-modifying potential of anti-hyperglycemic agents.

In this cohort study, we followed up a representative sample of the Taiwanese population for 12 years to determine the effect on risk for $\mathrm{AD}$ of T2DM, with and without OAA therapy, using a matching protocol to mimic a clinical trial $[24,29,30]$.

\section{Methods}

\section{Ethics approval}

This study was approved by the institutional review board of the National Health Research Institutes of Taiwan.

\section{Data sources and study subjects}

Taiwan began a national health insurance (NHI) program in 1995. By 2007, 98.4\% of Taiwan's 22.96 million population was enrolled in the program. Subject to a double scrambling protocol, the NHI Research Database is based on the registration files and original claims data for reimbursement. The Longitudinal Health Insurance Database 2000 contains all the original claims data of 800,000 beneficiaries, randomly sampled from the year 2000. We studied this database with antecedent data from 1 January 1996.

We conducted two studies with different objectives: the first to determine the effect of diabetes on AD incidence, and the second to ascertain the effect of sulfonylureas or metformin, or a combination of both, on AD. 


\section{Study 1}

To determine the effect of diabetes on AD incidence, we first formed a cohort of 762,753 participants with consistent data, who were registered as NHI beneficiaries on 1 January 2000 (Figure 1). They were followed up during the period 1 January 1996 to 31 December 2007. Assessing subjects aged 20 years or above, diabetes was found to be present in 62,988, and absent in the remaining 699,765. Of those with T2DM, 40,232 used any
OAA and 22,756 used none. People with T2DM were matched for birth date and gender with those who were diabetes-free, in order to compare AD incidence. Any individual in a matched pair who had previous $A D$ was excluded (Figure 1A). There were 60,646 pairs successfully matched, of which 39,159 pairs were on OAAs and 21,487 pairs were not.

Subjects with T2DM were defined as those who had at least two records of diabetes (ICD-9, CM-250 or A181;

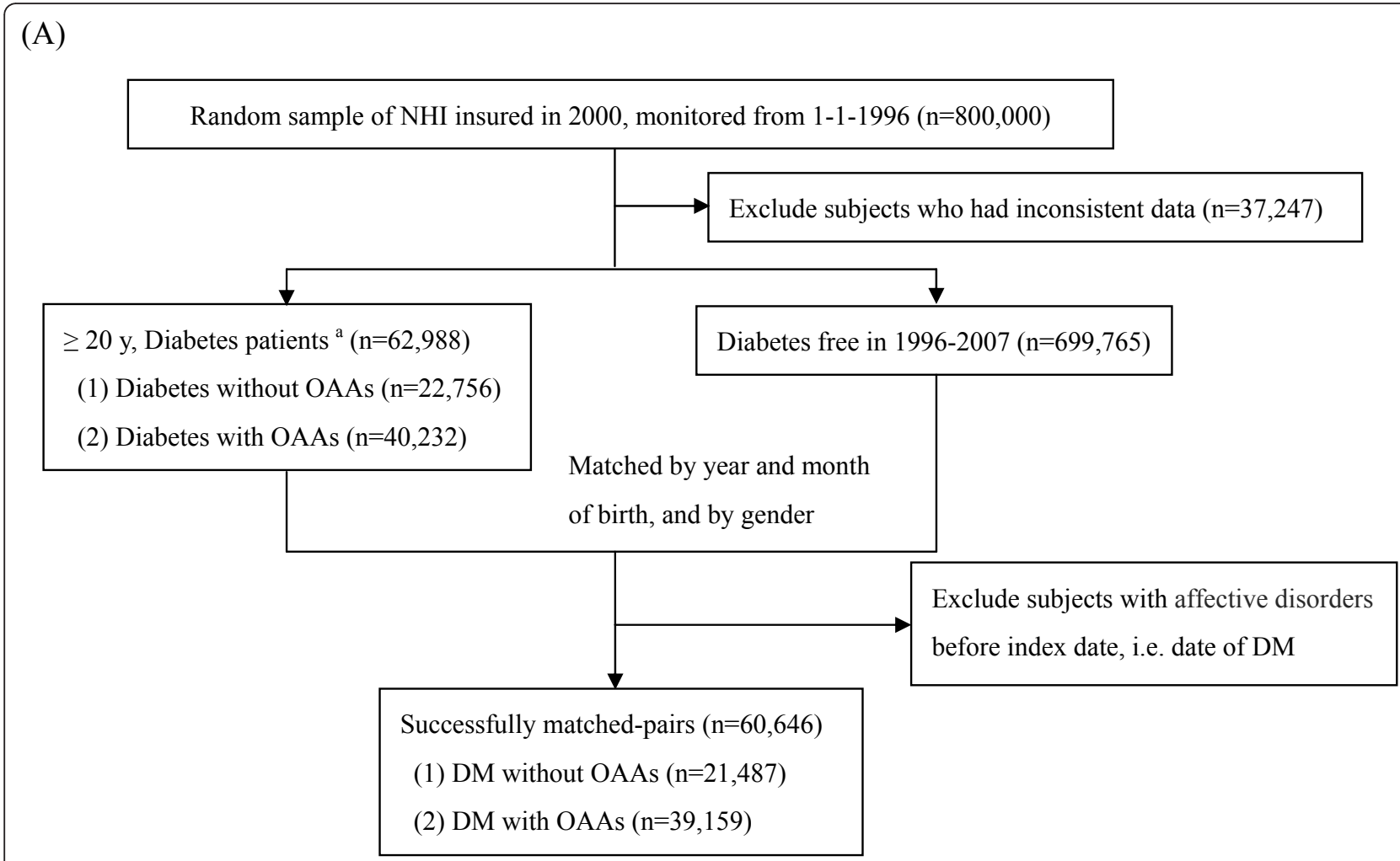

(B)

\section{DM patients}

\begin{tabular}{|l|l|}
\hline No DM diagnosis & Diabetes \\
\hline & Diabetes diagnostic (index) date, \\
\hline
\end{tabular}

\section{Gender-DOB-Matched DM-free adults}

\section{No DM diagnosis}

Figure 1 Patient selection and index date assignment for Study 1. (A) Flow chart of selection of patients with diabetes for comparison of affective disorder (AD) risk with subjects who were free of both diabetes and AD. Subjects aged 20 years or over with a diagnosis of type 2 diabetes mellitus (T2DM) recorded more than once within 1 year or who had used any oral anti-hyperglycemic agent (OAA) for at least 3 months during the period 1996 to 2007 regardless of insulin usage, were evaluated. (B) Follow-up of AD onset; patients with diabetes mellitus (DM), who did or did not use oral anti-diabetic agents (OAA). were matched with diabetes-free counterparts, who had the same index dates as the DM diagnostic date. 
the latter was a diabetes code for ambulatory visits used in Taiwan before 2000) within any year during the period 1996 to 2007, or had used any OAA for more than 3 months. In the same matched pair, the subject with T2DM and the T2DM-free subject had the same diabetes diagnostic date (index date) for follow-up (Figure 1B).

The subjects with diabetes were classified into those using or not using OAAs during the follow-up period. We compared the incidence of AD between three groups (T2DM-free, T2DM on OAA, and T2DM without OAA). An AD incident case was defined as one with at least two records of the diagnosis of an AD (A212, or ICD-9 CM coding 296.0 to 296.9, which covers major or unipolar depression (296.2 and 296.3) and bipolar disorders (all other 296.0 to 296.9 , but not dysthymic disorders) within any year during the period 1996 to 2007, but after the diagnosis of diabetes. There were 19,009 AD cases in all: 12.073 unipolar and 6.936 bipolar.

\section{Study 2}

We further investigated the preventive effect of the OAAs metformin and/or sulfonylureas for future AD in subjects with T2DM. Metformin or sulfonylureas are the most commonly used OAAs for T2DM treatment in Taiwan. To avoid immortal time bias $[24,29,30]$, we matched patients with T2DM without OAAs and those on metformin or sulfonylureas by age, gender, region, level of care, and Charlson Comorbidity Index (CCI) [31]. In the same matched pair, the subjects with T2DM who were on metformin or sulfonylureas and those who were not on any OAA had the same date (treatment initiation date) for follow-up (Figure 2). Where necessary, a patient in the comparison group was used more than once.

We further classified subjects with T2DM on metformin or sulfonylureas into three groups: metformin only (1,509 pairs), sulfonylureas only (2,904 pairs), and a combination of these two drugs (5,397 pairs). The AD incidences of the three groups were compared with the subjects with T2DM who were not on OAAs (referent group). An insulin user was defined as any subject who had used it for more than 3 months; those who used insulin briefly during hospitalization were not counted as users.

\section{Matching factors}

Subjects' baseline status and comorbidity were treated as matching factors. Comorbidity was measured by the CCI [31] using the NHI diagnoses recorded in the year before the diagnosis of diabetes. For CCI score calculation, we did not include the diagnoses of T2DM because this disease was considered separately in its own right. Other factors included age (in groups aged 50 to 54,55 to 5960 to 64,65 to 69 , and $\geq 70$ years), gender, locality, and health service.

\section{Statistical analysis}

The differences between groups were evaluated by oneway ANOVA (CCI score) or $\chi^{2}$ test (demographics). For the effect of diabetes on future $\mathrm{AD}$, the diabetes diagnostic date was used as the starting point to calculate survival time (Figure 1B). For the preventive effect of metformin or sulfonylureas on future depression in subjects with T2DM, the treatment initiation date was used as the starting point to calculate survival time (Figure $2 \mathrm{~B}$ ). The end of followup was the onset date of $\mathrm{AD}$ or the date of withdrawal from the NHI program or the end of 2007, whichever occurred first. AD incidence density was defined as the number of incident AD events divided by 10,000 personyears at risk.

We used Cox proportional-hazards models to evaluate associations between diabetes, OAAs, and AD. In addition to matching, adjustments were made for monthly income (0, 1 to $15,000,15,000$ to 21000 , and $>21000 \mathrm{New}$ Taiwan Dollars (NTD)) and use of insulin (yes or no). The statistics software SAS (version 9.1, SAS Institute, Cary, NC, USA) was used for data management and modeling. These models were evaluated using the progressive annual exclusion of incident AD for 3 years after the diagnosis of diabetes. A two-sided $P$-value of $<0.05$ was considered significant.

\section{Results}

The hazard ratio (HR) and 95\% confidence interval (CI) for AD in those with T2DM and not on OAAs were compared with those who were diabetes-free, and matched for age and gender (Figure 3). The increase in risk was 2.62fold (95\% CI 2.31 to 2.98). For subjects with T2DM who were on any OAA, compared with those who were diabetes-free, the HR of 1.06 (0.96 to 1.16 ) was not significant, but it represented a normalization of that for T2DM without OAA therapy. The analogous findings by gender and whether AD was unipolar or bipolar are also shown. These indicate that the effects of diabetes and of OAA are similar for men and women and are irrespective of AD polarity.

We calculated the prevalences of T2DM and AD for the year 2000, and plotted them by age (Figure 4). Both prevalences were seen to increase with age, although that for diabetes is more striking than for AD. The steepest increase for diabetes prevalence was between the ages of 40 and 60 years. This informed our choice of 50 years as the age for study 2, as we considered the effects of OAA on the incidence of $\mathrm{AD}$ may be more related to diabetes in these subjects than in younger subjects. When each of unipolar and bipolar AD prevalences were considered, those for unipolar AD were found to increase with age, but there was little increase for bipolar AD.

The demographics were stratified according to each metformin or sulfonylurea category, and matched with 


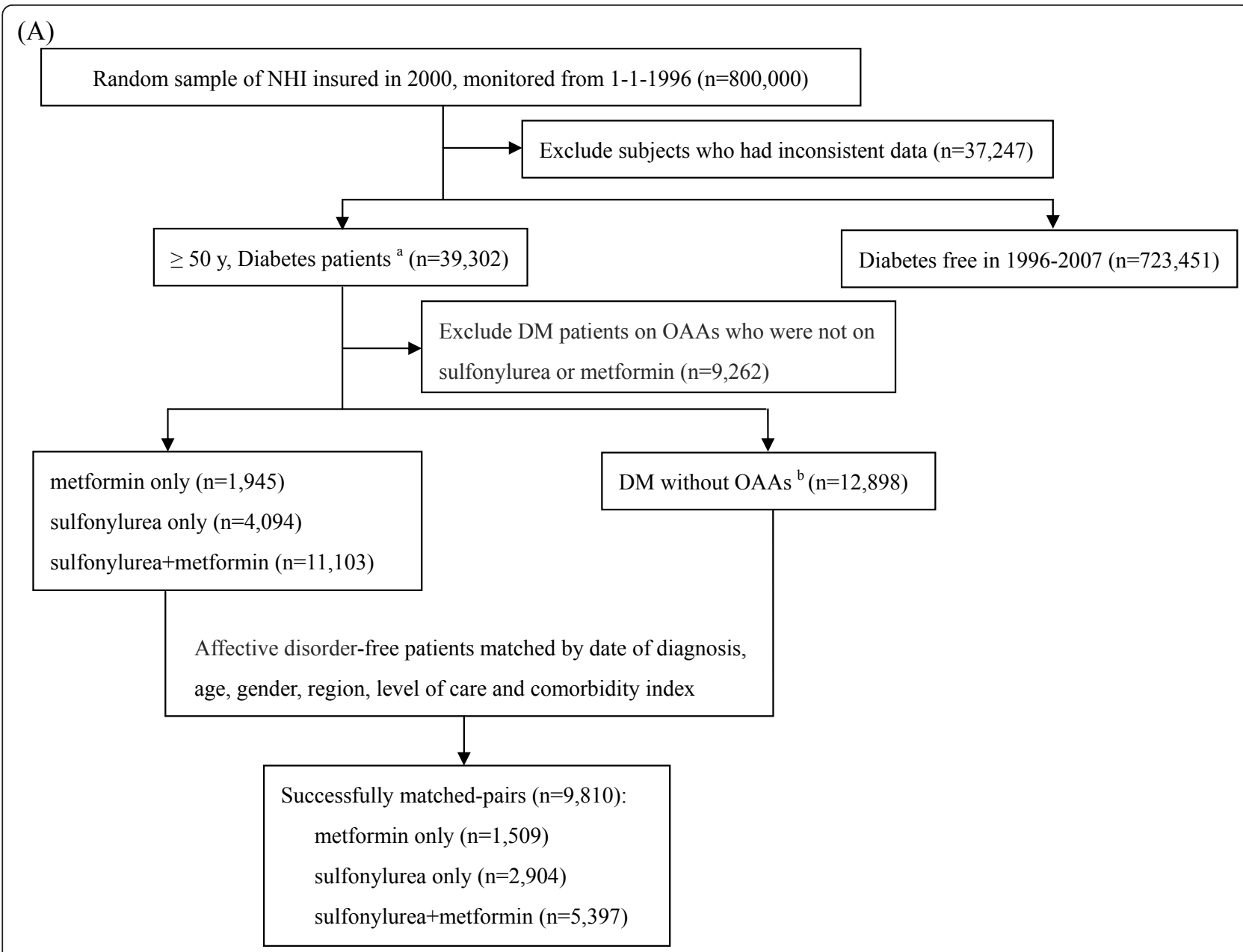

(B)

DM with SU+/or Met

\begin{tabular}{|l|l|l|}
\hline No DM diagnosis & DM & SUt/or Met \\
\hline & $\begin{array}{l}\text { Diabetes } \\
\text { diagnostic date }\end{array}$ & Treatment initiation date \\
\hline No DM diagnosis & DM with no OAA \\
\hline
\end{tabular}

Figure 2 Patient selection and index date assignment for Study 2. (A) Flow chart of selection of patients with type 2 diabetes who did not have affective disorder (AD) for assessment of AD incidence. Subjects aged 50 years or over with a diagnosis of type 2 diabetes recorded more than once within 1 year or who had used any oral anti-hyperglycemic agent (OAA) for at least 3 months during the period 1996 to 2007, regardless of insulin usage. (B) Patients with no OAA exposure were eligible to serve in the matching process for the various OAA groups. Subjects with diabetes on sulfonylureas (SU) and/or metformin (Met) and their matched non-OAA treated counterparts had the same treatment initiation dates (that is, index dates) for follow-up of AD.

those with T2DM who had had no OAA (Table 1). There were 9,810 patients with T2DM who were on an OAA and who could be matched with those without an OAA for assessment of AD incidence density and risk of AD. Neither sulfonylureas nor metformin alone were associated with a significant change in AD incidence. For the combination of metformin and sulfonylurea, the incidence density decreased from 91.1 to 39.4 per 


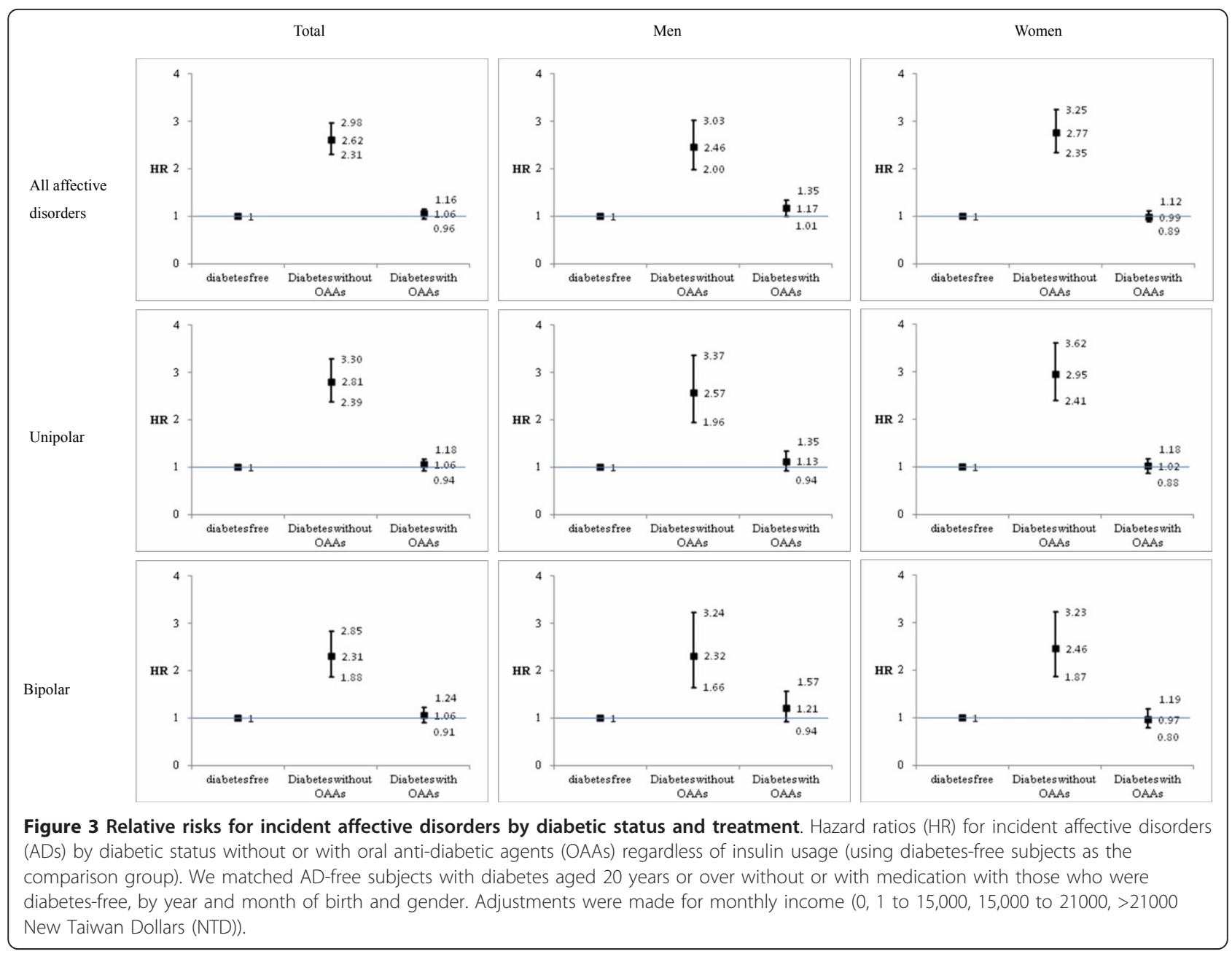

10,000 person-years when men and women were considered together, and the findings were similar for both genders (Table 2).

The HRs for sulfonylurea and/or metformin therapy were compared with the subjects with T2DM but not on OAAs as the referent group (Table 3). Sulfonylurea or metformin alone had no significant effect on $A D$ risk.; however, the combined treatment resulted in an evident reduction in $\mathrm{AD}$ risk of $60 \%(\mathrm{HR}=0.40 ; 95 \% \mathrm{CI}$ 0.32 to 0.50$)$. The findings were similar ( $\mathrm{HR}=0.42 ; 95 \%$ CI 0.33 to 0.53 ) after adjustment for monthly income and insulin usage. To eliminate any effect of insulin in combination with OAAs, a sub-analysis excluded all insulin users; the findings remained unchanged (data

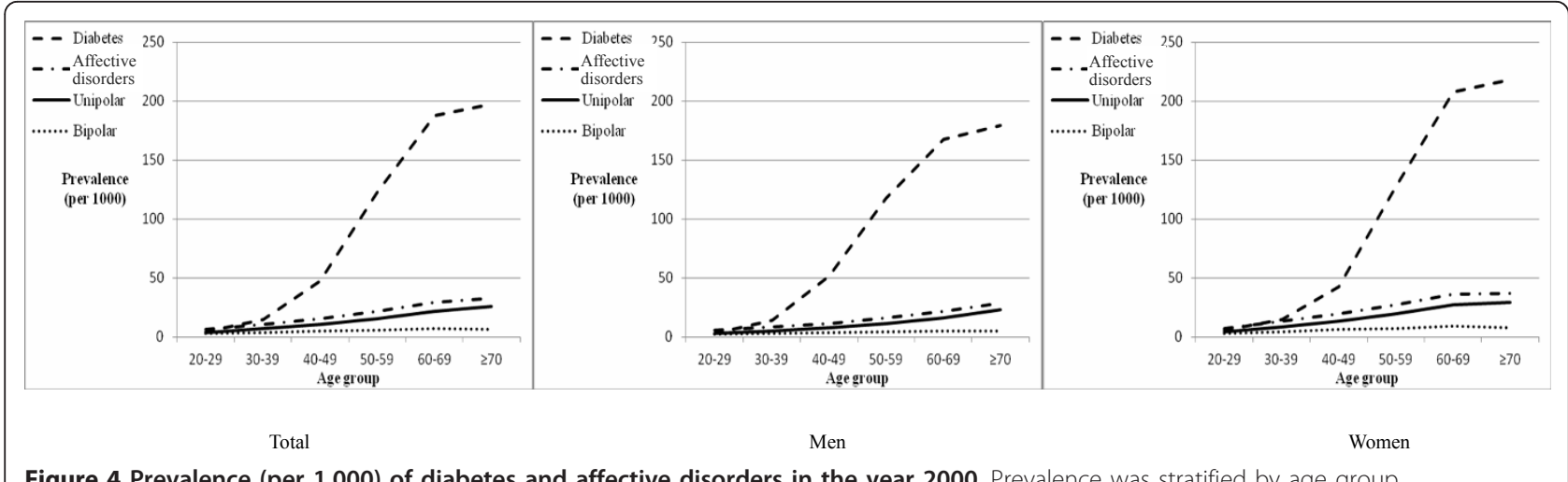

Figure 4 Prevalence (per 1,000) of diabetes and affective disorders in the year 2000. Prevalence was stratified by age group. 
Table 1 Demographics for affective disorder (AD)-free patients with diabetes (DM) using oral anti-hyperglycemic agents (OAAs) and their matched counterparts without OAA

\begin{tabular}{|c|c|c|c|c|c|}
\hline \multirow[b]{2}{*}{ Descriptor } & \multicolumn{2}{|l|}{ Study 1} & \multicolumn{3}{|l|}{ Study 2} \\
\hline & $\begin{array}{l}\text { DM without OAAs } \\
(n=21,487)\end{array}$ & $\begin{array}{l}\text { DM with OAAs } \\
(\mathrm{n}=39,159)\end{array}$ & $\begin{array}{l}\text { Met only } \\
(n=1509)\end{array}$ & $\begin{array}{l}\text { SUs onlyc } \\
(n=2904)\end{array}$ & $\begin{array}{l}\text { SUs + Met }{ }^{d} \\
(n=5397)\end{array}$ \\
\hline \multicolumn{6}{|l|}{ Age, mean $\pm S D$ years } \\
\hline For matched pair & $56.0 \pm 15.2$ & $57.5 \pm 12.3$ & $67.7 \pm 9.1$ & $67.7 \pm 9.1$ & $65.7 \pm 8.9$ \\
\hline At DM diagnosis, & $56.0 \pm 15.2$ & $57.5 \pm 12.3$ & $67.5 \pm 8.7$ & $67.5 \pm 8.7$ & $65.3 \pm 8.2$ \\
\hline \multicolumn{6}{|l|}{ Age groups, years } \\
\hline$<50$ & 35.8 & 28.6 & & & \\
\hline 50 to 54 & 11.9 & 13.8 & 6.0 & 6.8 & 10.3 \\
\hline 55 to 59 & 11.2 & 13.9 & 16.7 & 16.6 & 20.2 \\
\hline 60 to 64 & 10.1 & 13.9 & 19.3 & 17.7 & 20.4 \\
\hline 65 to 69 & 10.4 & 12.9 & 18.8 & 19.4 & 19.0 \\
\hline$\geq 70$ & 20.6 & 16.3 & 39.2 & 39.6 & 30.1 \\
\hline Female gender & 52.3 & 48.3 & 54.5 & 50.8 & 52.5 \\
\hline \multicolumn{6}{|l|}{ Locality } \\
\hline North & 46.5 & 42.2 & 54.2 & 41.8 & 45.9 \\
\hline Central & 22.3 & 22.8 & 18.2 & 20.8 & 21.4 \\
\hline South & 28.3 & 31.4 & 26.1 & 36.2 & 31.6 \\
\hline East & 2.35 & 2.94 & 1.5 & 1.1 & 1.1 \\
\hline Offshore & 0.66 & 0.66 & 0 & 0.10 & 0.11 \\
\hline \multicolumn{6}{|l|}{ Level of health service } \\
\hline Primary & 26.7 & 28.3 & 26.5 & 32.2 & 30.5 \\
\hline Secondary & 53.0 & 47.1 & 50.6 & 49.5 & 51.5 \\
\hline Tertiary & 20.3 & 24.6 & 22.9 & 18.3 & 18.0 \\
\hline Insulin user & 0.0 & 12.3 & 4.57 & 3.13 & 5.78 \\
\hline $\mathrm{CCl}$, mean $\pm \mathrm{SD}$ & & & $1.4 \pm 1.8$ & $1.6 \pm 2.1$ & $1.6 \pm 2.2$ \\
\hline
\end{tabular}

an total, there were 9,810 patients with DM who were free of affective disorder (AD) and were on oral anti-diabetic agents (OAA), and who could be matched for age, gender, locality, health service, Charlson Comorbidity Index and DM diagnosis date, with those who were free of AD and who were not on OAA. Where necessary, a patient in the comparison group was used more than once. Thus, there were 9,810 matched pairs. All values are percentages unless indicated.

batients diagnosed with DM and treated with metformin,(Met) who had never used insulin during the period 1996 to 2007.

'Patients diagnosed with DM and treated with sulfonylureas (SUs) who had never used insulin during the period 1996 to 2007.

dPatients diagnosed with DM and treated with both Met and SUs, who had never used insulin during the period 1996 to 2007.

not shown). The order of introduction of the drugs or whether they were introduced together or separately, did not alter the significance of this finding either. Similar results were evident with both unipolar and bipolar $\mathrm{AD}$, although more so with bipolar AD.

Although subjects were matched for $\mathrm{CCI}$ to minimize any effect on incident $\mathrm{AD}$ of underlying or latent disease at the time of diabetes treatment initiation, the incidences for the first 3 years were progressively excluded (Figure 5). The HRs for combined sulfonylurea and metformin remained significant into the third year for all incident $\mathrm{AD}$, at 0.67 (0.48 to 0.93 ). The findings are similar for both bipolar and unipolar AD, but there was a trend toward a greater reduction in bipolar AD.

\section{Discussion}

\section{Affective disorder and diabetes in Taiwan}

In this study, we found that for Taiwanese subjects with T2DM aged 50 years or over, having no oral anti-hyperglycemic therapy is a risk factor for $\mathrm{AD}$, with an overall increase in risk of 2.62-fold during the period 1996 to 2007. One reason our findings are not negative [11], unlike those of other studies [12-15], may be that they were not masked by therapeutic interventions for diabetes that we have previously found to reduce the risks of dementia [23] and Parkinson's disease [24]. Another is that in Taiwan, as elsewhere, the burden of diabetes in an ageing population is increasing [17], and thus the phenomenon is more recognizable. However, in some community-based ageing populations such as that of Australia, older people do not necessarily show an increased prevalence of depression [32]. It is possible that diabetes might play a greater role in the development of depression or AD in communities in which its prevalence increases to a greater extent in later life. Gender did not seem to influence the status of diabetes as a risk factor for $\mathrm{AD}$, whether unipolar or bipolar. This does not diminish the importance of gender differences in risk for depression or AD that have been recognized for other factors [32], or of the pathogenetic and clinical differences between the major types of $\mathrm{AD}$, but it 


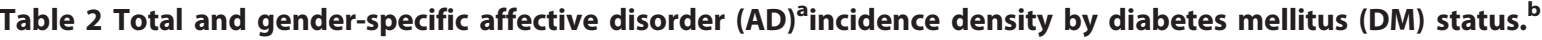

\begin{tabular}{|c|c|c|c|c|c|c|}
\hline \multirow[b]{2}{*}{ Descriptor } & \multicolumn{2}{|l|}{ Total } & \multicolumn{2}{|l|}{ Men } & \multicolumn{2}{|l|}{ Women } \\
\hline & $\begin{array}{l}\text { Cases/total study } \\
\text { group, } \mathrm{n}\end{array}$ & ID $(95 \% \mathrm{Cl})^{\mathrm{c}}$ & $\begin{array}{l}\text { Cases/total study } \\
\text { group, } \mathrm{n}\end{array}$ & ID $(95 \% \mathrm{Cl})^{\mathrm{c}}$ & $\begin{array}{l}\text { Cases/total study } \\
\text { group, } \mathrm{n}\end{array}$ & ID $(95 \% \mathrm{Cl})^{\mathrm{c}}$ \\
\hline $\begin{array}{l}\text { DM without } \\
\text { OAAs }\end{array}$ & $42 / 5619$ & $\begin{array}{l}74.7(52.2 \text { to } \\
97.3)\end{array}$ & $11 / 2599$ & $\begin{array}{l}42.3(17.4 \text { to } \\
67.3)\end{array}$ & $31 / 3019$ & $\begin{array}{l}102(66.7 \text { to } \\
138)\end{array}$ \\
\hline Met only & $43 / 5627$ & $\begin{array}{l}76.4(53.7 \text { to } \\
99.2)\end{array}$ & $18 / 2637$ & $\begin{array}{l}68.2(36.8 \text { to } \\
99.7)\end{array}$ & 25/2989 & $\begin{array}{l}83.6(51.0 \text { to } \\
116)\end{array}$ \\
\hline $\begin{array}{l}\text { DM without } \\
\text { OAAs }\end{array}$ & $140 / 14503$ & $\begin{array}{l}96.5 \text { (80.6 to } \\
112)\end{array}$ & $52 / 7101$ & $\begin{array}{l}73.2(53.4 \text { to } \\
93.1)\end{array}$ & $88 / 7402$ & $\begin{array}{l}118(94.2 \text { to } \\
143)\end{array}$ \\
\hline SUs only & $145 / 13370$ & $\begin{array}{l}108 \text { (90.9 to } \\
126)\end{array}$ & $59 / 6581$ & $\begin{array}{l}89.6(66.9 \text { to } \\
112)\end{array}$ & $86 / 6788$ & $\begin{array}{l}126(100 \text { to } \\
153)\end{array}$ \\
\hline $\begin{array}{l}\text { DM without } \\
\text { OAAs }\end{array}$ & 282/30957 & $\begin{array}{l}91.1 \text { ( }^{(80.5} \text { to } \\
101)^{d}\end{array}$ & $100 / 14064$ & $\begin{array}{l}71.1(57.2 \text { to } \\
85.0)^{\mathrm{e}}\end{array}$ & $182 / 16893$ & $\begin{array}{l}107(92.2 \text { to } \\
123)^{f}\end{array}$ \\
\hline SUs + Met & $127 / 32236$ & $\begin{array}{l}39.4(32.6 \text { to } \\
46.2)^{\mathrm{d}}\end{array}$ & 45/14791 & $\begin{array}{l}30.4(21.5 \text { to } \\
39.3)^{\mathrm{e}}\end{array}$ & $82 / 17444$ & $\begin{array}{l}47.0(36.9 \text { to } \\
57.2)^{f}\end{array}$ \\
\hline
\end{tabular}

${ }^{a} A D$ diagnoses include ICD-9-CM (296) and the equivalent Taiwanese A-code (A212).

${ }^{a}$ Met, metformin; OAAs: oral anti-diabetic agents; SUs, sulfonylureas.

ID $(95 \% \mathrm{Cl})$ : incidence density per 10,000 person-years ( $95 \%$ confidence interval).

${ }^{d-f}$ The same superscript vertically indicates that there is a significant difference between the two groups.

does emphasize the possible commonalities through the diabetes linkage and raises questions about which of these might be relevant in prevention and management.

There has been no study to date of T2DM and AD on East Asian populations, where marked increases in T2DM prevalence have occurred in recent years, and where almost half of the world's population is exposed to diabetes, and consequently to a potential threat to mental health. Our study makes a contribution to the relevance of diabetes as a risk factor for AD in East Asian populations, as Taiwan has a dominantly Chinese ethnic population and is therefore an example of a large under-studied group.

\section{Preventive or therapeutic benefit of oral anti- hyperglycemic agents for affective disorder}

The available studies have not considered diabetes pharmacotherapy in relation to the effect of diabetes on the risk for depression or AD, which may have led to lower estimates of the possible reduction in risk of AD by diabetes therapy. In the meta-analysis on Europeans and North Americans carried out by Nouwen et al. [12], the increased risk for depression was $24 \%$ and in the study by Nefs et al. [14], it was 14\%; given our findings, these were probably underestimates. We found the increased risk for incident $\mathrm{AD}$ in subjects with $\mathrm{T} 2 \mathrm{DM}$ untreated by OAA to be 2.6-fold (both unipolar and bipolar AD HRs were similar, at 2.81 and 2.31 , respectively), which suggests that the available studies have grossly underestimated the potential effect of diabetes in this area of mental health.

The combination of sulfonylurea and metformin significantly reduced both incidence and relative risk for $\mathrm{AD}$ in T2DM, irrespective of gender; there was no such change evident for sulfonylurea or metformin alone (Table 2, Table 3). It also did not matter in which order sulfonylurea or metformin were started. For any particular intervention, patients were extensively matched with their reference non-OAA subject, using counterparts with the same date of diabetes diagnosis, within the same calendar year. This reduced the possibility that a change in accepted diabetes management might have accounted for the observed effects, whether in men or women. Bias, especially from time, was minimized, and thus made this cohort study more similar to a clinical trial $[29,30]$. Differences in referent subjects between treatment categories were addressed by matching for matters such as accessibility to care (by locality), level of care (by primary to tertiary or medical center) and associated health status (CCI) (Table 3).

Despite adjustment for co-morbidities and the exclusion of incident $\mathrm{AD}$ for up to 3 years after introduction of OAA therapy, the combination of sulfonylurea and metformin was still associated with HRs of less than $1.00 \mathrm{com}-$ pared with no OAA therapy. This applied to both unipolar and, to a greater extent, bipolar AD. Thus, although differences between these two forms of AD are well documented and with agreed therapies, our findings raise the possibility that there are some common underlying pathogenetic factors, perhaps related to neurodegeneration.

The findings for the sulfonylurea/metformin combination rather than either alone would be consistent with synergistic or complimentary mechanisms of action of the two agents. Because advanced glycation end-products are found in the central nervous system (CNS), specifically in microglia [33], these two OAAs together might act via a more pronounced anti-hyperglycemic effect. Such an effect might be combined with specific AD-reduction 
Table 3 Hazard ratios (HRs) and 95\% confidence intervals (Cls) for affective disorders (ADs) by date of diabetes diagnosis and diabetes mellitus (DM) treatment. ${ }^{a, b}$

\begin{tabular}{|c|c|c|c|c|c|c|c|}
\hline \multirow[b]{2}{*}{ Descriptor } & \multicolumn{3}{|l|}{$A D s^{c}$} & \multicolumn{2}{|l|}{ Unipolar $^{d}$} & \multicolumn{2}{|l|}{ Bipolar $^{e}$} \\
\hline & Cases/total study group, $\mathrm{n}$ & HR $(95 \%$ Cl) & HR $(95 \% \mathrm{Cl})^{f}$ & Cases/total study group, $\mathrm{n}$ & $\operatorname{HR}(95 \% \mathrm{Cl})^{\mathrm{f}}$ & Cases/total study group, $\mathrm{n}$ & HR $(95 \% \mathrm{Cl})^{\mathrm{f}}$ \\
\hline DM without OAA & $42 / 1509$ & Ref. & Ref. & $25 / 1509$ & Ref. & $17 / 1509$ & Ref. \\
\hline \multirow[t]{2}{*}{ Metformin only } & $43 / 1509$ & 0.92 & 1.00 & 29/1509 & 1.28 & $14 / 1509$ & 0.61 \\
\hline & & (0.59 to 1.45$)$ & (0.61 to 1.64$)$ & & (0.68 to 2.40$)$ & & (0.22 to 1.65$)$ \\
\hline DM without OAA & $140 / 2904$ & Ref. & Ref. & 96/2904 & Ref. & $44 / 20904$ & Ref. \\
\hline \multirow[t]{2}{*}{ Sulfonylureas only } & $145 / 2904$ & 1.08 & 1.13 & $97 / 2904$ & 1.14 & $48 / 2904$ & 1.10 \\
\hline & & (0.84 to 1.38$)$ & (0.87 to 1.47$)$ & & (0.83 to 1.56$)$ & & (0.68 to 1.78$)$ \\
\hline DM without OAA & 282/5397 & Ref. & Ref. & 189/5397 & Ref. & $93 / 5397$ & Ref. \\
\hline \multirow[t]{2}{*}{ Sulfonylureas+ Metformin } & $127 / 5397$ & 0.40 & 0.42 & $83 / 5397$ & 0.44 & $44 / 5397$ & 0.38 \\
\hline & & $(0.32 \text { to } 0.50)^{i}$ & $(0.33 \text { to } 0.53)^{i}$ & & $(0.33 \text { to } 0.60)^{i}$ & & $(0.25 \text { to } 0.58)^{i}$ \\
\hline DM without OAA & $157 / 2843$ & Ref. & Ref. & $109 / 2843$ & Ref. & $48 / 2843$ & Ref. \\
\hline \multirow[t]{2}{*}{ SU+Met (SU first) } & $60 / 2843$ & 0.32 & 0.33 & $36 / 2843$ & 0.32 & $24 / 2843$ & 0.37 \\
\hline & & $(0.23 \text { to } 0.44)^{i}$ & $(0.23 \text { to } 0.47)^{i}$ & & $(0.21 \text { to } 0.50)^{i}$ & & $(0.20 \text { to } 0.68)^{i}$ \\
\hline DM without OAA & $33 / 968$ & Ref. & Ref. & $18 / 968$ & Ref. & $15 / 968$ & Ref. \\
\hline \multirow[t]{2}{*}{ SU+Met (Met first) } & 19/968 & 0.53 & 0.45 & 10/968 & 0.45 & 9/968 & 0.50 \\
\hline & & $(0.29 \text { to } 0.98)^{9}$ & $(0.23 \text { to } 0.89)^{9}$ & & (0.17 to 1.17$)$ & & (0.18 to 1.36$)$ \\
\hline DM without OAA & $92 / 1586$ & Ref. & Ref. & $62 / 1586$ & Ref. & $30 / 1586$ & Ref. \\
\hline \multirow[t]{2}{*}{ SU+Met (the same time) } & $48 / 1586$ & 0.50 & 0.54 & $37 / 1586$ & 0.65 & $11 / 1586$ & 0.32 \\
\hline & & $(0.35 \text { to } 0.72)^{i}$ & $(0.36 \text { to } 0.82)^{i}$ & & (0.40 to 1.04$)$ & & $(0.14 \text { to } 0.75)^{h}$ \\
\hline
\end{tabular}

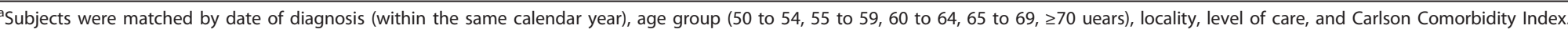
OAAs: oral anti-diabetic agents; SU: sulfonylureas; Met: metformin; Ref, reference

IInternational Classification of Diseases(ICD) code 296.

dICD: 296.2, 296.3,

ICD: 296.0, 296.1, 296.4, 296.5, 296.6, 296.7, 296.8, 296.9

Adjusted for monthly income (0, 1-15,000, 15,000-21000, >21000 NTD) and insulin usage (yes, no).

${ }^{g-i}$ Significance: ${ }^{\mathrm{g}} P<0.05,{ }^{\mathrm{h}} P<0.01,{ }^{\mathrm{i}} P<0.001$. 


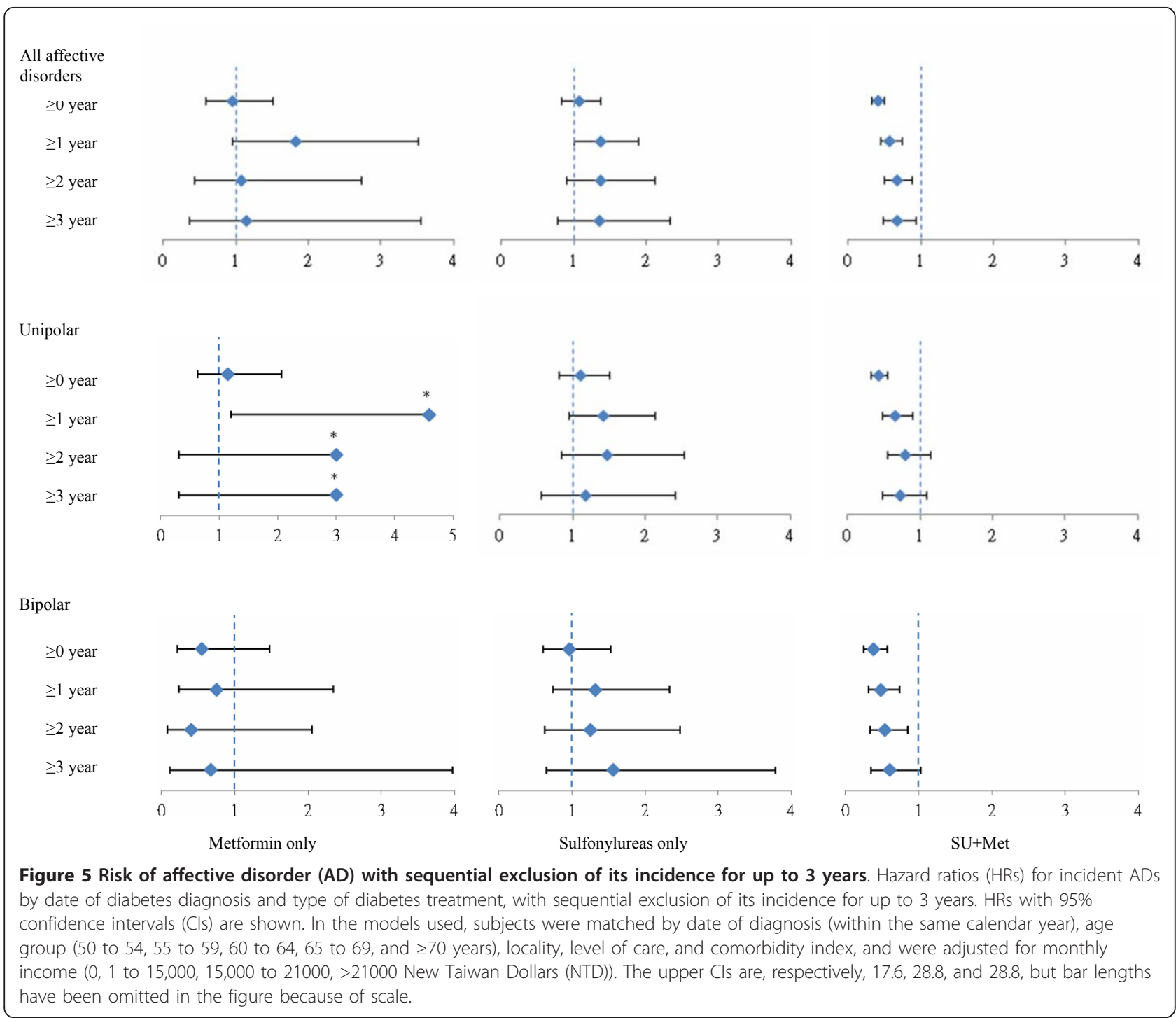

actions of the drugs. As mentioned above, metformin might operate through mechanisms that are protective against neurodegeneration, if this is a shared pathogenesis with $\mathrm{AD}$. When diabetes affects the CNS, AD might share underlying mechanisms with neurodegenerative diseases such as dementia and Parkinsonism [23,24]. We previously reported that T2DM also increases the risk of dementia by 2.6 -fold, and that the combination of sulfonylureas and metformin was able to decrease the risk of dementia in diabetes within 12-years [23], with similar findings in PD [24]. These collective findings strengthen the case for a linkage between brain diabetes, neurodegenerative disease, and $\mathrm{AD}$, a conjunction already in evidence from various pathophysiological studies [33,34]. Chen et al.. found that metformin might increase the biogenesis of amyloid peptides in Alzheimer's disease, which could be relevant if there is a shared pathogenesis with depression, so our population-wide study supports this idea [35].
The definition of OAA usage in our models was a prescription for at least 3 months. Minimal doses for metformin were equivalent to about $500 \mathrm{mg}$ per day and, for sulfonylureas, one standard tablet or capsule per day. These therapeutic regimens are feasible for most people with T2DM, and may largely remove the risk of AD posed by diabetes within 12 years of starting treatment. Owing to the limited number of subjects with T2DM on insulin therapy in this study, we did not treat them separately. Controlling for or exclusion of insulin usage in the models made no difference to our findings about OAAs and AD.

\section{Issues in the diagnosis of affective disorder in diabetes}

The Taiwanese NHI claim data rely on the medical service utilization of patients and on medical diagnoses. Underdiagnosis of AD and DM is likely if the reach of a healthcare system is limited, but NHI covers more than 
98\% of the population in Taiwan and, with the use of our matching protocol for accessibility (that is, region, level of service, and income), underdiagnosis should have been minimized. For social reasons, AD may be under-reported, but this is less likely with diabetes because of frequent and more intensive contact with the health system. Nevertheless, clinicians may have a tendency to simplify the diagnostic list when patients have multisystem diseases such as diabetes, in favor of the 'less pressing' diagnoses, which might therefore mean less recording of $\mathrm{AD}$.

We have no information about the diagnosis of either diabetes or AD before 1996, when the NHI started, but it is unlikely that the presence of either of these would not have been recorded by a medical practitioner at some subsequent consultation. However, because the diagnosis of bipolar AD depends on at least two visits, such conditions may have been under-diagnosed as a consequence. Thus, there are several factors which may affect $\mathrm{AD}$ diagnosis rates, and thus their net effect on the differentials with regard to antecedent diabetes remains unclear.

A valuable insight into the validity of these diagnostic rates comes from the relevance of diagnostic methods, whether questionnaire or psychiatric diagnosis [12]. Differences in estimates have been found to be dependent on year of publication of the report, but also to be probably increasing with time. Thus, there are questions about how contemporary our work, using 1996 datasets, might be regarded, because, as an NHI system requirement, we used ICD-9 for the diagnosis of AD rather then ICD-10 or DSM-IV. The ICD-9 codes used in the present study were 296.0 to 296.9 and its Taiwanese coding counterpart was A212 (before year 2000); nevertheless, these do cover ICD-10 codes F30 to F33 and F38 to F39, and thus, our study should be replicable.

We recognize that using the DSM-IV would have been a more useful approach to the diagnosis of depression and, more particularly, mood or AD, because it includes clinical symptoms and other axes that would have provided more analytical scope. However, it is reassuring that there can be some convergence of the risk assessment for diabetes on depression or AD, even using different methods [12]. At the same time, our large and representative populationbased study has allowed a more detailed understanding of the association of diabetes with different mood disorders than would otherwise have been possible.

\section{Limitations}

In our study of $\mathrm{AD}$, we considered both its unipolar and bipolar forms, but not dysthymic disorders, thus our findings are not applicable to all forms of depression. With regard to diabetes as a risk factor for AD, there seems to be no gender difference. Nor did we find any apparent difference between unipolar and bipolar AD, although sample size may have been limiting. Because incident $\mathrm{AD}$ was progressively excluded in the models, sample size diminished. Therefore, we may not have been able to discern more substantial and longer-term differences between unipolar and bipolar AD insofar as OAA effects are concerned.

T2DM and depression or AD seem to be at least bidirectional, if not mutually reinforcing $[10,36]$. This process may begin at an early stage in the evolution of diabetes from pre-diabetic states and in the early stages of depressive illness. We did not study pre-diabetes subjects, but we did track individuals through what will have been that phase, from being diabetes-free in the 1996 to 2007 cohort. From other evidence [10,36], we cannot fully exclude effects on depression-induced diabetes, which may have, in turn, increased AD incidence.

The study cohort is an administrative sample for which measures of diabetes severity are not available. Therefore, we do not have dose-response data for the studied OAAs and glycemic control. However, we can say that this particular OAA combination changes the risk for $\mathrm{AD}$ in T2DM, what the minimal dosages are likely to be for protection against $\mathrm{AD}$, and how long it might take for these effects to be evident, as these informed the method we used to establish exposures. Matching for CCI, which partly represents diabetes-related complications and its severity, make it more likely that we observed a genuine OAA effect rather than one simply of glycemic control, although the latter is still possible.

Although ours is not an intervention study, we found at least one OAA combination which could enhance risk reduction for AD. This is unlikely to be a surrogate for other potential determinants of risk like body mass index. Moreover, were this combination of sulfonylurea and metformin to operate to reduce AD risk through a possible surrogate like body mass index, it might well be that these OAA act in directions opposite from each other, given their known opposite effects on body mass index. Unfortunately, these covariates are unavailable.

\section{Implications}

It is difficult to say how early or late in the course of diabetes it may be possible for OAAs to reduce the risk of $\mathrm{AD}$, but if the association is causal and has an underlying pathogenesis shared with neurodegeneration, then the responsive period is likely to be earlier rather than later. Therefore, the early recognition of those at risk for diabetes may allow reduction in the burden of depression. It is now recommended that metformin should form part of the therapeutic management of T2DM as early in its course as possible because of the superior cardiovascular and all-cause mortality outcomes with this drug compared with other OAAs [37]. We consider that a broader view of 
diabetes comorbidity and its management will stimulate interest in changing diabetes therapeutics, with the prospects of a significant reduction in the burden of disease seen with the tandem of diabetes and AD.

\section{Conclusions}

In a large cohort representative of the Taiwanese population, followed for up to 12 years, T2DM increased the risk of AD 2.6-fold. However, the HR for AD for patients taking combined sulfonylurea and metformin remained significantly decreased into the third year for all incident $\mathrm{AD}$ at 0.67 (0.48 to 0.93), and this was evident for both bipolar and unipolar AD. As the global burden of diabetes increases, these findings may be relevant to the reduction of its mental-health complications.

\begin{abstract}
Abbreviations
AD: affective disorders; CCl: Charlson Comorbidity Index; Cl: confidence interval; CNS: central nervous system; HR: hazard ratio; NHI: National Health Insurance; OAA: oral anti-hyperglycemic agent; T2DM: type 2 diabetes.
\end{abstract}

\section{Acknowledgements}

We gratefully acknowledge the support of the Department of Health and the Bureau of National Health Insurance in Taiwan for their encouragement and cooperation in the conduct of this investigation. All authors report no financial relationships with commercial interests.

\begin{abstract}
Author details
'Division of Preventive Medicine and Health Services Research, Institute of Population Health Sciences, National Health Research Institutes, 35 Keyan Road, Zhunan Town, Miaoli, Taiwan 35053, ROC. ${ }^{2}$ School of Public Health, National Defense Medical Center, 161 Minchuan East Road, Sec 6, Taipei, Taiwan 114, ROC. ${ }^{3}$ Monash Asia Institute, Monash University, 900 Dandenong Road, Caulfield East, Victoria 3145, Australia. ${ }^{4}$ Department of Epidemiology and Preventive Medicine, Monash University, 99 Commercial Road, Melbourne, Victoria 3004 Australia. ${ }^{5}$ Department of Health Services Administration, China Medical University and Hospital, 91 Hsueh-Shih Road, Taichung, Taiwan 40402, ROC. ${ }^{6}$ Department of Psychiatry, Chung Shan Medical University Hospital, 110, Sec 1, Jianguo North Road, Taichung, Taiwan 40201, ROC. ${ }^{7}$ Department of Psychiatry, Chung Shan Medical University, No. 110, Sec 1, Chien Kuo N. Road, Taichung, Taiwan 40201, ROC.
\end{abstract}

\section{Authors' contributions}

MLW, MSL, CCH, and SYC designed the study; MLW, MSL and CCH managed the study; MLW, CCH, MSL, and HNT analyzed and interpreted the data; MLW wrote the paper; MLW, MSL, SYC, CCH, HNT, SHY and HYC read, revised and approved the final manuscript

\section{Competing interests}

The authors declare that they have no competing interests.

Received: 17 May 2012 Accepted: 29 November 2012 Published: 29 November 2012

\section{References}

1. Koenigsberg HW, Klausner E, Pelino D, Rosnick P, Campbell R: Expressed emotion and glucose control in insulin-dependent diabetes mellitus. Am J Psychiatry 1993, 150:1114-1115.

2. Stabler B, Surwit RS, Lane JD, Morris MA, Litton J, Feinglos MN: Type A behavior pattern and blood glucose control in diabetic children. Psychosom Med 1987, 49:313-316.

3. Anderson RJ, Freedland KE, Clouse RE, Lustman PJ: The prevalence of comorbid depression in adults with diabetes: a meta-analysis. Diabetes Care 2001, 24:1069-1078.
4. Arroyo C, Hu FB, Ryan LM, Kawachi I, Colditz GA, Speizer FE, Manson J: Depressive symptoms and risk of type 2 diabetes in women. Diabetes Care 2004, 27:129-133.

5. Engum A: The role of depression and anxiety in onset of diabetes in a large population-based study. J Psychosom Res 2007, 62:31-38.

6. Kessler RC, Chiu WT, Demler O, Merikangas KR, Walters EE: Prevalence, severity, and comorbidity of 12-month DSM-IV disorders in the National Comorbidity Survey Replication. Arch Gen Psychiatry 2005, 62:617-627.

7. Lustman PJ, Griffith LS, Freedland KE, Clouse RE: The course of major depression in diabetes. Gen Hosp Psychiatry 1997, 19:138-143.

8. Musselman DL, Betan E, Larsen H, Phillips LS: Relationship of depression to diabetes types 1 and 2: epidemiology, biology, and treatment. Biol Psychiatry 2003, 54:317-329.

9. Palinkas LA, Lee PP, Barrett-Connor E: A prospective study of type 2 diabetes and depressive symptoms in the elderly: the Rancho Bernardo Study. Diabet Med 2004, 21:1185-1191.

10. Pan A, Lucas M, Sun Q, van Dam RM, Franco OH, Manson JE, Willett WC, Ascherio A, Hu FB: Bidirectional association between depression and type 2 diabetes mellitus in women. Arch Intern Med 2010, 170:1884-1891.

11. Brown LC, Majumdar SR, Newman SC, Johnson JA: Type 2 diabetes does not increase risk of depression. CMAJ 2006, 175:42-46.

12. Nouwen A, Winkley K, Twisk J, Lloyd CE, Peyrot M, Ismail K, Pouwer F, European Depression in Diabetes (EDID) Research Consortium: Type 2 diabetes mellitus as a risk factor for the onset of depression: a systematic review and meta-analysis. Diabetologia 2010, 53:2480-2486.

13. Nouwen A, Nefs G, Caramlau I, Connock M, Winkley K, Lloyd CE, Peyrot M, Pouwer F, European Depression in Diabetes Research Consortium: Prevalence of depression in individuals with impaired glucose metabolism or undiagnosed diabetes: a systematic review and metaanalysis of the European Depression in Diabetes (EDID) Research Consortium. Diabetes Care 2011, 34:752-762.

14. Nefs G, Pouwer F, Denollet J, Pop V: The course of depressive symptoms in primary care patients with type 2 diabetes: results from the Diabetes, Depression, Type D Personality Zuidoost-Brabant (DiaDDZoB) Study. Diabetologia 2012, 55:608-616.

15. Mezuk B, Eaton WW, Albrecht S, Golden SH: Depression and type 2 diabetes over the lifespan: a meta-analysis. Diabetes Care 2008, 31:2383-2390.

16. Campayo A, de Jonge P, Roy JF, Saz P, de la Camara C, Quintanilla MA, Marcos G, Santabarbara J, Lobo A: Depressive disorder and incident diabetes mellitus: the effect of characteristics of depression. $\mathrm{Am} J$ Psychiatry 2010, 167:580-588.

17. Chang HY, Hsu CC, Pan WH, Liu WL, Cheng JY, Tseng CH, Bai CH, Yeh WT, Hurng BS: Gender differences in trends in diabetes prevalence from 1993 to 2008 in Taiwan. Diabetes Res Clin Pract 2010, 90:358-364.

18. Weissman MM, Bland RC, Canino GJ, Faravelli C, Greenwald S, Hwu HG, Joyce PR, Karam EG, Lee CK, Lellouch J, Lépine JP, Newman SC, RubioStipec M, Wells JE, Wickramaratne PJ, Wittchen H, Yeh EK: Cross-national epidemiology of major depression and bipolar disorder. JAMA 1996, 276:293-299.

19. Chong MY, Tsang HY, Chen CS, Tang TC, Chen CC, Yeh TL, Lee YH, Lo HY: Community study of depression in old age in Taiwan: prevalence, life events and socio-demographic correlates. Br J Psychiatry 2001, 178:29-35.

20. Huang CQ, Zhang XM, Dong BR, Lu ZC, Yue JR, Liu QX: Health status and risk for depression among the elderly: a meta-analysis of published literature. Age Ageing 2010, 39:23-30.

21. Evans JM, Donnelly LA, Emslie-Smith AM, Alessi DR, Morris AD: Metformin and reduced risk of cancer in diabetic patients. BMJ 2005, 330:1304-1305.

22. Lee MS, Hsu CC, Wahlqvist ML, Tsai HN, Chang YH, Huang YC: Type 2 diabetes increases and metformin reduces total, colorectal, liver and pancreatic cancer incidences in Taiwanese: a representative population prospective cohort study of 800,000 individuals. BMC Cancer 2011, 11:20

23. Hsu CC, Wahlquist ML, Lee MS, Tsai HN: Incidence of dementia is increased in type 2 diabetes and reduced by the use of sulfonylureas and metformin. J Alzheimers Dis 2011, 24:485-493.

24. Wahlqvist ML, Lee MS, Hsu CC, Chuang SY, Lee JT, Tsai HN: Metformininclusive sulfonylurea therapy reduces the risk of Parkinson's disease occurring with Type 2 diabetes in a Taiwanese population cohort. Parkinsonism Relat Disord 2012, 18:753-758.

25. Kickstein E, Krauss $S$, Thornhill P, Rutschow D, Zeller R, Sharkey J, Williamson R, Fuchs M, Kohler A, Glossmann H, Schneider R, Sutherland C, 
Schweiger S: Biguanide metformin acts on tau phosphorylation via mTOR/protein phosphatase 2A (PP2A) signaling. Proc Natl Acad Sci USA 2010, 107:21830-21835.

26. Rapp MA, Schnaider-Beeri M, Purohit DP, Perl DP, Haroutunian V, Sano M: Increased neurofibrillary tangles in patients with Alzheimer disease with comorbid depression. Am J Geriatr Psychiatry 2008, 16:168-174.

27. Leroy K, Ando K, Heraud C, Yilmaz Z, Authelet M, Boeynaems JM, Buee L, De Decker R, Brion JP: Lithium treatment arrests the development of neurofibrillary tangles in mutant tau transgenic mice with advanced neurofibrillary pathology. J Alzheimers Dis 2010, 19:705-719.

28. Cohen ST, Welch G, Jacobson AM, De Groot M, Samson J: The association of lifetime psychiatric illness and increased retinopathy in patients with type I diabetes mellitus. Psychosomatics 1997, 38:98-108.

29. Levesque LE, Hanley JA, Kezouh A, Suissa S: Problem of immortal time bias in cohort studies: example using statins for preventing progression of diabetes. BMJ 2010, 340:b5087.

30. Suissa S: Immortal time bias in pharmaco-epidemiology. Am J Epidemiol 2008, 167:492-499

31. Charlson ME, Pompei P, Ales KL, MacKenzie CR: A new method of classifying prognostic comorbidity in longitudinal studies: development and validation. J Chron Dis 1987, 40:373-383.

32. Profile of depression in Australia. [http://www.health.gov.au/internet/main/ publishing.nsf/content/8E0E3BC67E3962AFCA25712B0080235F/\$File/nhpa2. pdf].

33. Khazaei MR, Habibi-Rezaei M, Karimzadeh F, Moosavi-Movahedi AA, Sarrafnejhad AA, Sabouni F, Bakhti M: Microglial cell death induced by glycated bovine serum albumin: nitric oxide involvement. J Biochem 2008, 144:197-206

34. Pomara N, Bruno D, Sarreal AS, Hernando RT, Nierenberg J, Petkova E, Sidtis JJ, Wisniewski TM, Mehta PD, Pratico D, Zetterberg H, Blennow K: Lower CSF amyloid beta peptides and higher F2-isoprostanes in cognitively intact elderly individuals with major depressive disorder. Am J Psychiatry 2012, 169:523-530.

35. Chen Y, Zhou K, Wang R, Liu Y, Kwak YD, Ma T, Thompson RC, Zhao Y, Smith L, Luo Z, Xu H, Liao FFL: Antidiabetic drug metformin (GlucophageR) increases biogenesis of Alzheimer's amyloid peptides via up-regulating BACE1 transcription. Proc Natl Acad Sci USA 2009, 106:3907-3912.

36. Golden SH, Lazo M, Carnethon M, Bertoni AG, Schreiner PJ, Diez Roux AV, Lee HB, Lyketsos C: Examining a bidirectional association between depressive symptoms and diabetes. JAMA 2008, 299:2751-2759.

37. Johnson JA, Majumdar SR, Simpson SH, Toth EL: Decreased mortality associated with the use of metformin compared with sulfonylurea monotherapy in type 2 diabetes. Diabetes Care 2002, 25:2244-2248.

\section{Pre-publication history}

The pre-publication history for this paper can be accessed here: http://www.biomedcentral.com/1741-7015/10/150/prepub

doi:10.1186/1741-7015-10-150

Cite this article as: Wahlqvist et al:: Increased risk of affective disorders in type 2 diabetes is minimized by sulfonylurea and metformin combination: a population-based cohort study. BMC Medicine 2012 10:150.

\section{Submit your next manuscript to BioMed Central and take full advantage of:}

- Convenient online submission

- Thorough peer review

- No space constraints or color figure charges

- Immediate publication on acceptance

- Inclusion in PubMed, CAS, Scopus and Google Scholar

- Research which is freely available for redistribution 